\title{
Hydrogen Energy System and Environmental Impact Factor
}

\author{
Ken-ichiro Ota, * Akimitsu Ishinara, Koichi Matsuzawa, and Shigenori Mitsushima
}

Yokohama National University, Graduate School of Engineering (79-5 Tokiwadai, Hodogaya-ku, Yokohama 240-8501, Japan)

Received June 12, 2010 ; Accepted September 27, 2010

\begin{abstract}
In order to develop our society, human beings should consider the global environment where global cycles of materials are essentially important. Considering a global effect of an energy carrier such as hydrogen and hydrocarbons, the hydrogen cycle (water cycle) is compared with the carbon cycle in order to evaluate the effect of an energy carrier on natural cycles of materials. We introduced a new parameter named "Environmental impact factor". The environmental impact factor was defined as a ratio of an annual quantity of materials produced by energy consumption of mankind to a natural movement on the earth. The environmental impact factor of water on the earth, 0.0001, is two orders of magnitude less than that of carbon/carbon dioxide, 0.036 . This result means that the hydrogen/water cycle is superior to the carbon cycle considering the materials circulation for energy system of mankind on a global scale. In addition, we applied the environmental impact factor to cities and prefectures in Japan. The environmental impact factor of water was always smaller than that of carbon in all cities and prefectures in Japan. This result indicates that hydrogen energy is friendly to the environment.
\end{abstract}

Key Words : Hydrogen Energy, Environment, Impact Factor, Sustainable Growth

\section{Introduction}

More than 200 years has passed after the industrial revolution and we are using many technologies in order to have a wealthy life. We are also using energy to apply these technologies. Now we are going to use a huge amount of energy to keep our life style or to get a higher life, so that we need more energy. Many people are anxious about the global warming caused by the large usage of fossil fuels.

We, human beings, have several serious problems such as economy, environment and energy which should be solved in order to sustain activities of the civilization. Among them, the energy problem should be solved and a clean energy system should be constructed in the near future. Although these issues are generally called energy problems, they should consider related to the entropy problems. A viewpoint of entropy is very important when energy and environment are discussed, because all activities on the Earth including the human beings cause entropy production according to the second law of thermodynamics with the conservation law of materials and energy. Entropy governs a direction of all changes, so that the entropy production should be considered in order to sustain the activity of human society. Several studies related to entropy were performed when a desirable energy system of the civilization was planned.1-3) However, little has mentioned the relation of the entropy disposal and the stability of the civilization. In this paper, the role of the material circulation from the viewpoint of the entropy was discussed at first. The ideal energy system which mankind should pursue is considered next. The water cycle caused by the hydrogen energy system on the earth was compared with the carbon cycle which is caused by the usage of fossil fuels. The hydrogen- based energy system using the renewable energy is thought to be an ideal clean energy system. We are going to evaluate the hydrogen energy system more quantitatively compared with the present fossil energy system which causes the global warming.

\section{Relation of Self-regulating Systems and Materials Circulation}

Schrödinger pointed out that the entropy concept was important when living systems were considered in a physico-chemical standpoint. ${ }^{4)}$ He proposed the new term of negentropy to explain that the living systems, which could be called as self-regulating systems, assimilated the low entropy materials and always emitted the entropy produced with their activities to maintain the ordered structures and functions. Self-regulating systems are almost open systems because the entropy of an isolated system monotonously increases until it reaches its maximum value at the state of thermodynamic equilibrium, that is, a dead state. Prigogine extended the second law of thermodynamics to open systems that exchange energy and materials with their surroundings, and formulated the entropy balance as a following equation. ${ }^{5}$

$$
\mathrm{dS}=\mathrm{d}_{\mathrm{e}} \mathrm{S}+\mathrm{d}_{\mathrm{i}} \mathrm{S} \quad \mathrm{d}_{\mathrm{i}} \mathrm{S} \geq 0
$$

where $d_{e} S$ is the transfer of entropy across the boundaries of an open system and could be positive, negative, or zero, and $\mathrm{d}_{\mathrm{i}} \mathrm{S}$ was the entropy produced within the system. Produced entropy $\mathrm{d}_{\mathrm{i}} \mathrm{S}$ is equal to zero for reversible process and $\mathrm{d}_{\mathrm{i}} \mathrm{S}$ is always positive for irreversible process. According to this formulation, the basic differences between reversible and irreversible processes become clear. In order to maintain the constant value 
of the entropy of an open system with spontaneous change (that is, $d S=0$ ), $d_{e} S$ must be negative because $\mathrm{d}_{\mathrm{i}} \mathrm{S}$ is always positive. A. Tsuchida emphasized that materials circulation was essentially important for selfregulating systems to eliminate the produced entropy. ${ }^{6}$ However, there were few qualitative discussions on the role of materials circulation to maintain the stability of an open system.

A primary purpose of the self-regulating systems included with an ecosystem and a local community as well as organisms is to maintain their stability. According to the second law of thermodynamics, any activity on the earth always increases the total entropy. Therefore, the entropy produced with the activity of the self-regulating systems must be disposed of in order to maintain its steady state. The role of materials on the sustainability of activity and the constant disposal of entropy is quantitatively discussed based on examples. Metabolism of living system and photosynthesis were considered as examples. The related reaction equations and their change of entropies are summarized in Table 1. Most of living systems obtain the energy of activity by an aerobic respiration presented as Eq. (1-2). And the entropy change of Eq. (1-2) allowed the inverse reaction of Eq. (1-3) to proceed. This process takes place by the compensation effect of entropy (coupling reaction). Furthermore, biosynthesis, active transport and mechanical work could occur by the energy change of a spontaneous reaction from ATP to ADP (the forward reaction of Eq. (3)) to maintain the self-regulating activity, and

Table 1 Related reaction equation of metabolism of living system and photosynthesis, and their entropy change calculated from Gibbs energy and enthalpy data. ${ }^{7,8}$

\begin{tabular}{ll|c|c|c}
\hline Reaction equation & & $\begin{array}{c}\text { Total } \\
\text { entropy } \\
\text { change }\end{array}$ & $\begin{array}{c}\text { Entropy } \\
\text { change due } \\
\text { to energy }\end{array}$ & $\begin{array}{c}\text { Entropy } \\
\text { change due } \\
\text { to material }\end{array}$ \\
\hline Sunlight $\rightarrow$ Infrared wave & $(1-1)$ & +235 & +235 & 0 \\
\hline $\mathrm{C}_{6} \mathrm{H}_{12} \mathrm{O}_{6}+6 \mathrm{H}_{2} \mathrm{O}+6 \mathrm{O}_{2} \rightarrow 6 \mathrm{CO}_{2}+12 \mathrm{H}_{2} \mathrm{O}$ & $(1-2)$ & +9.6 & +9.4 & +0.2 \\
\hline $36 \mathrm{ATP}+36 \mathrm{H}_{2} \mathrm{O} \rightarrow 36 \mathrm{ADP}+36 \mathrm{H}_{3} \mathrm{PO}_{4}$ & $(1-3)$ & +3.7 & +2.5 & +1.2 \\
\hline
\end{tabular}

$298 \mathrm{~K}, 1 \mathrm{~atm}$ Unit : $\mathrm{kJ} / \mathrm{K}$ and per 1 mole of $\mathrm{C}_{6} \mathrm{H}_{12} \mathrm{O}_{6}$

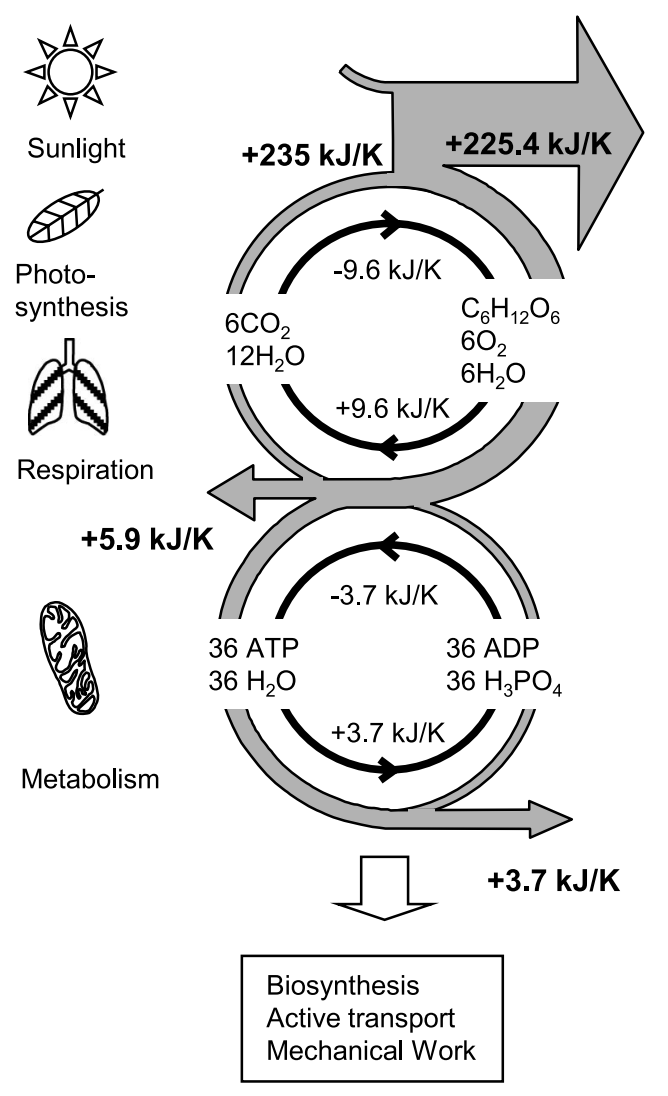

(a) Total entropy flow

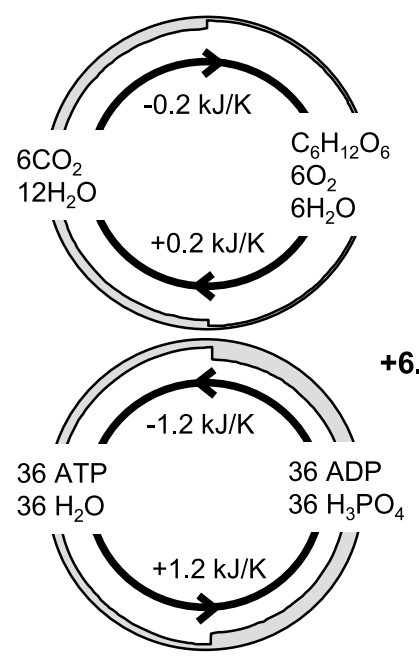

(b) Entropy flow due to material

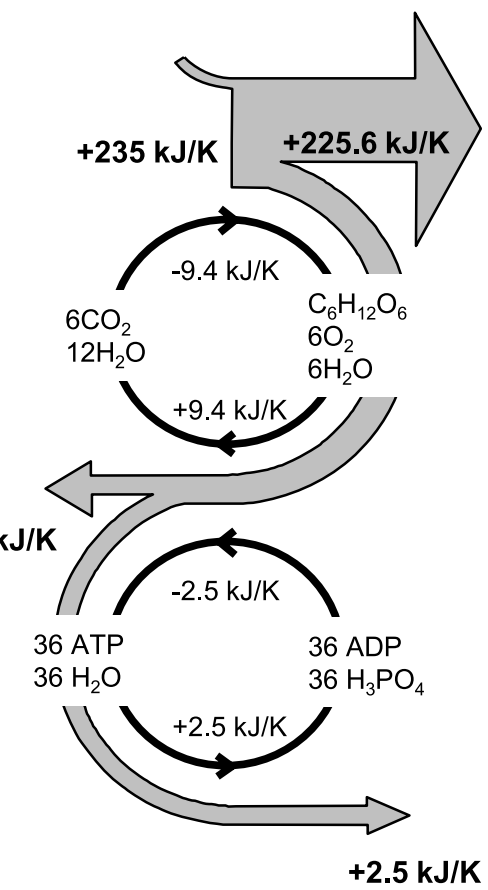

(c) Entropy flow due to energy

Fig. 1 Schematic diagram of the total entropy flow, the entropy flow due to materials and energy in relation to metabolism of living system and photosynthesis. 
total entropy was simultaneously produced. ATP and ADP alternately changed, that is, circulated. All produced entropy in this process released to the outside of the system in a form of heat.

The produced entropy with aerobic respiration should be constantly released outside (environment). This entropy disposal was performed with the release of $\mathrm{CO}_{2}$, $\mathrm{H}_{2} \mathrm{O}$ and heat. It is also necessary that the environment exports the entropy released from the self-regulating system outside to maintain its steady state. The steady state of the self-regulating system in the environment cannot be preserved when the produced entropy is accumulated in the environment. Regarding energy balance, the earth is always supplied with the sunlight of low entropy, and the infrared radiation of high entropy can be disposed out to space. Therefore, related to energy, the large flow from the sunlight with the long-wave thermal radiation helps to maintain the steady state. The thermal entropy from metabolism of the living system can be disposed through this large entropy flow.

On the other hand, regarding materials, the earth is nearly a closed system. That is, the entropy of materials can not be disposed as a waste material to the outside of the earth. In order to maintain the constant aerobic respiration it is essential that the environment needs a mechanism in which $\mathrm{CO}_{2}$ and $\mathrm{H}_{2} \mathrm{O}$ will return to glucose (organic substances) and $\mathrm{O}_{2}$. This becomes possible by photosynthesis which uses the compensation effect of sunlight of low entropy as shown in Eq. (1-1).

As a whole, the photosynthesis regenerates glucose and $\mathrm{O}_{2}$, indicating that all entropy is in the form of heat. As a result of a series of the process, the circulation of materials takes place and the entropy which is produced by the self-regulating activity is entirely disposed to the space as an irradiative heat.

Figure 1 schematically showed the situation. Figure 1 (a) showed the total entropy flow, and the participated material's circulation to form the closed system as a whole of the earth. The entropy flow of materials corresponded to the situation of (a) is shown in Fig.1 (b). It is shown that the entropy of materials circulates corresponding to materials circulation and is not disposed to outside. The flow of the entropy with thermal form is also shown in Fig. 1 (c). In Fig. 1 (c), the entropy change which is released to outside as expressed by bold-type letters is the entropy which is disposed through each process as heat. These values are different from the values of the total entropy change governed the direction of the change. Since the entropy value with the change from sunlight to infrared radiation is $+235.0 \mathrm{~kJ} / \mathrm{K}$, the total amount of the entropy change is equal to that of disposed entropy as heat.

From these discussions, it was found that the self-regulating activity needed the materials circulation. The produced entropy could be disposed to space as heat by means of a chain of the materials circulation. The total quantity of entropy production with sunlight would be invariable even if there were the self-regulating activity or not.

Materials are circulated by the use of the low entropy of sunlight, and the low entropy is transferred to maintain the self-regulating activity by a chain of the materials circulation. This is an ideal state, where the constancy and the stability of the earth including the self-regulating systems are guaranteed.

\section{Ideal Energy System Consisted on Materials Circulation}

A human society is one of the typical self-regulating systems. In order to sustain the steady state of human society including its energy system, all the materials should be permanently circulated. And the produced entropy should be disposed off always as a long-wave thermal radiation to space. This situation is schematically represented in Fig. 2. This is an ideal steady state of the earth including the civilization. It is desirable that the ideal energy system of the human society is also based on materials circulation, which originally takes place on the earth.

The primary energy is presently fossil fuels. However, it should be moved toward renewable sources. The energy quantity imported from the sun to the earth is $1.24 \times$ $10^{14} \mathrm{~kW}$. Whereas, an energy consumption of human beings is merely 0.02 when the energy imported from the sun is assumed to be 100 . The energy consumption of human beings could be satisfied with the renewable energy from the sun which is drenched now and a few years ago from the viewpoint of quantity. However, it is presently impossible to fulfill the energy consumption of our human society by the renewable energies because of the low energy density, an uneven distribution, and a time fluctuation of the renewable energy. Science and technology do not advance enough to realize that, and there are many technical problems to be solved. But, the energy system using the renewable energy would be our final target of a clean energy system. If we think that the primary energy of an ideal energy system is supplied by a renewable energy, the next problem is what kind of materials should be selected as a secondary energy. From the viewpoint of entropy, the ideal energy supply system must be based on the materials circulation.

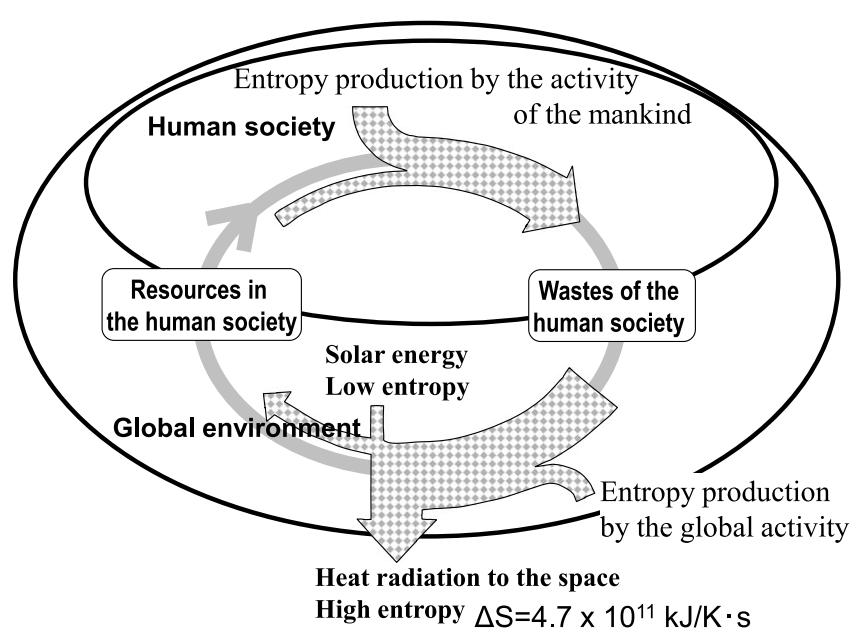

Fig. 2 Entropy flow of the human society and the Earth for the sustainable society. 
When hydrogen is chosen as a secondary energy, the circulation of water, which is oxidative state of hydrogen, can be used. On the other hand, when hydrocarbon is chosen as a secondary energy, the circulation of carbon as well as water is utilized. Water cycle is compared with carbon cycle in relation to a material circulation which human beings can utilize for a clean energy system. A water cycle presently plays an important role in the entropy disposal of the earth.9,10) Abundance and circulation of water on the earth ${ }^{11,12)}$ are shown in Fig. 3. An amount of the evaporation of water is $520 \mathrm{~T}$ ton/year, and it is equal to the amount of the rainfall. Water in the atmosphere exchanged about 10 days. Figure 4 showed carbon cycle ${ }^{13)}$ in the present earth. The transfer amount of carbon between the atmosphere and the surface are $157 \mathrm{G}$ ton/year. Carbon in the atmosphere exchanged about 5 years. Since the human has

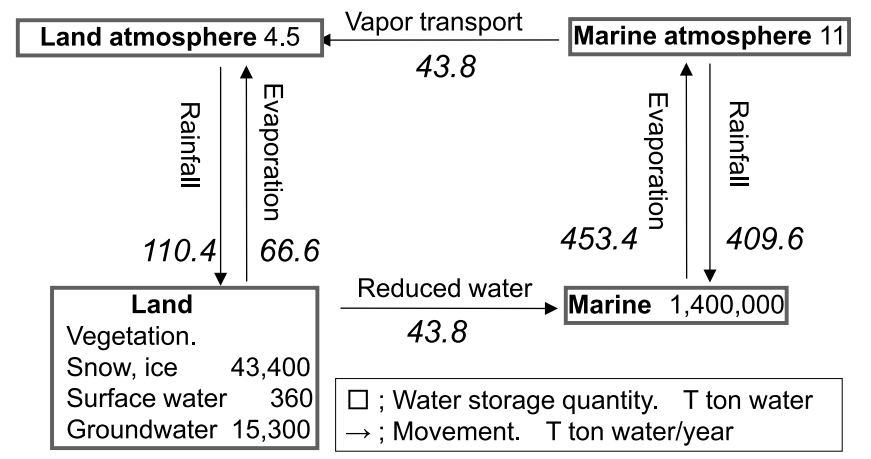

Fig. 3 Schematic diagram of the water cycle on the Earth.

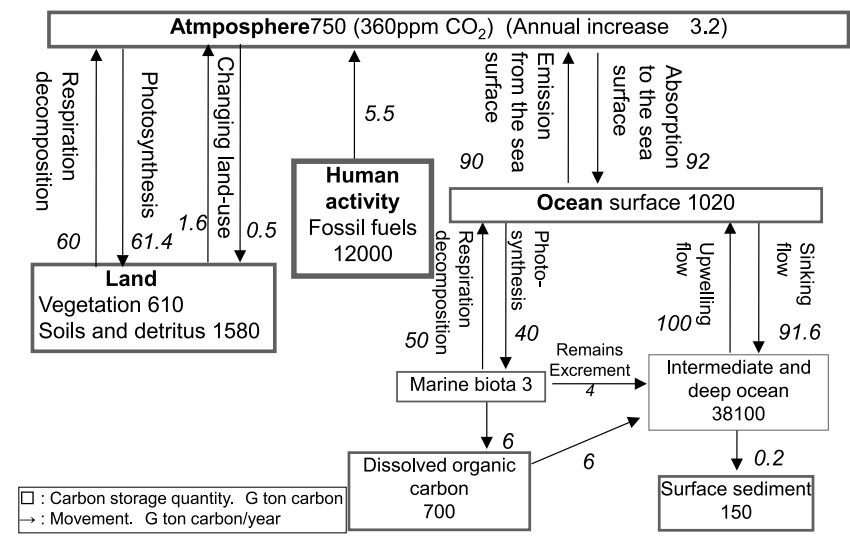

Fig. 4 Schematic diagram of the carbon cycle on the Earth. been largely consuming the fossil fuel to discharge $\mathrm{CO}_{2}$ into the atmosphere, the $\mathrm{CO}_{2}$ concentration has been gradually increasing. We should select a good circulation system on the earth from which the effect of our activities is smaller. When all of the secondary energies such as hydrogen and hydrocarbons are supplied from renewable energies only, the renewable energy causes the circulations of carbon and water even if we do not use for the energy resources. If we used renewable energies as the energy resources to produce hydrogen and hydrocarbon, they turn to water, $\mathrm{CO}_{2}$ and heat after usage. It looks that no additional environmental load generates. However, it is not true. Since the part of the natural circulation introduced into the human society, the spatial structure of the original global circulation is affected to change. From this point of view, we have to think the cycle of energy carriers. Either water or carbon affects smaller to the natural global circulation when we use. This is an important point.

Table 2 shows the comparison of carbon and water on the earth. The total abundance of water is much greater than that of carbon. Water exists 27,000 times larger in weight than carbon dioxide. The water abundance in the atmosphere is also larger about 21 times than the carbon abundance in the weight ratio. The material circulation with larger abundance in natural might be less affected by our human activity. The annual movement from the atmosphere of water is 3160 times larger than that of carbon, so that a large difference occurs in the mean residence time in the atmosphere. In comparison with the carbon cycle, the water cycle might be received a smaller effect by our activity.

The effect of the consumption of human beings on the natural carbon and the natural water cycles are quantitatively compared. At present, the increase quantity of carbon in the form of $\mathrm{CO}_{2}$ in the atmosphere by the consumption of the fossil fuels by mankind was estimated to be about 5.5 G ton carbon/year. Assuming that the same quantity of carbon from renewable energies is utilized, this quantity of carbon corresponds to $0.7 \%$ of carbon in the atmosphere, and $3.6 \%$ of the annual transfer quantity from the atmosphere.

The combustion heat of hydrogen is $143 \mathrm{~kJ} / \mathrm{g}$. This figure was utilized to evaluate the effect on the water cycle. The annual energy consumption of human beings is $6.0-8.2 \times 10^{17} \mathrm{~kJ}(2000)$. If all the energy used the hydrogen energy system (hydrogen/water combination), the production quantity of water due to this energy con-

Table 2 Comparison between water cycle and carbon cycle.

\begin{tabular}{|c|c|c|c|}
\hline & carbon & $\Rightarrow$ & water \\
\hline Total amount & $54 \mathrm{~T}$ ton & 27,000 Times & $1,460,000 \mathrm{~T}$ ton \\
\hline Atmosphere abundance & $750 \mathrm{G}$ to & 21 Times & $15.5 \mathrm{~T}$ ton \\
\hline $\begin{array}{c}\text { Annual movement from } \\
\text { atmosphere }\end{array}$ & $152 \mathrm{G}$ ton/year & 3,160 Times & $496 \mathrm{~T}$ ton/year \\
\hline $\begin{array}{l}\text { Average retention period } \\
\text { in atmosphere }\end{array}$ & 5 year & 180 Times & 10 day \\
\hline
\end{tabular}


sumption is calculated to be $38-52 \mathrm{G}$ ton. This is about $0.3 \%$ of vapor in atmosphere and the same order as carbon. However, it becomes very small value of $0.01 \%$ if it is considered in the relation to the annual movement from atmosphere. The ratio of the energy consumption of human beings to the annual movement from atmosphere of water is more than two orders of magnitude less than that of carbon. Because the annual movement from atmosphere is different at 3160 times, the effect of artificial spatial change is largely different from that of carbon. The water cycle is superior to the carbon cycle. The hydrogen-based energy system utilizes the water cycle. From the viewpoint of entropy flow, the hydrogenbased energy society is the ideal energy system which the human should pursue, where the materials circulation is almost perfect and the entropy can be thrown out by heat. Figure 5 shows an ideal hydrogen-based energy system using the water cycle.

\section{Environmental Impact Factor}

Considering the dynamic flow of energy carriers, we can define the environmental impact factor (EIF) of carbon and hydrogen as follows.

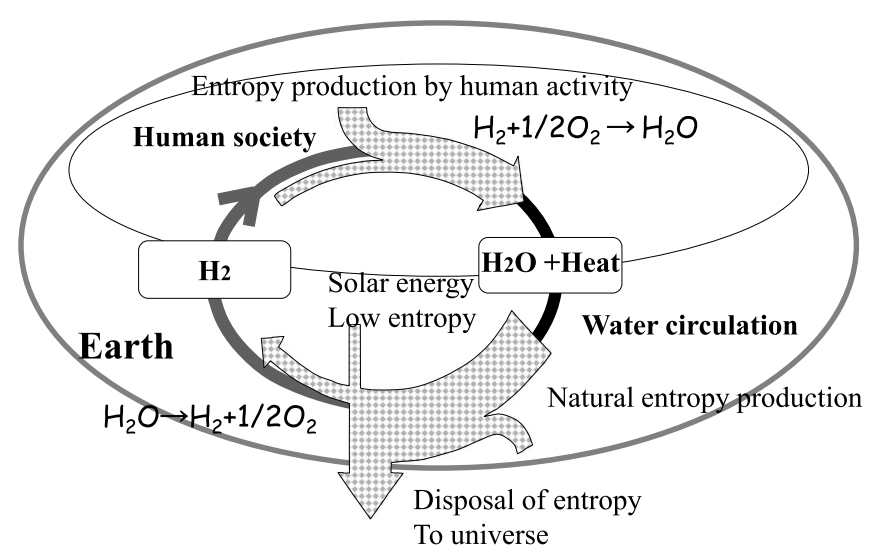

Fig. 5 Hydrogen energy and water circulation.

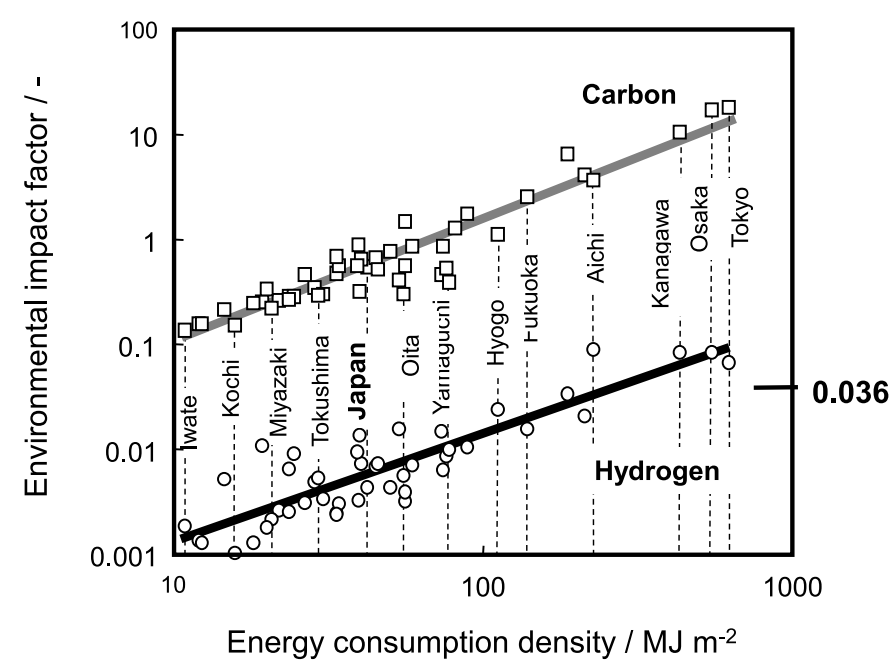

Fig. 6 Local environmental impact factor (EIF) vs. energy consumption of prefectures in Japan.

\author{
EIF of Carbon $=$ \\ Carbon $\left(\mathrm{CO}_{2}\right)$ Emission by Fossil Fuel Consumption \\ Natural Carbon $\left(\mathrm{CO}_{2}\right)$ Circulation
}

$$
\begin{aligned}
& \text { EIF of Hydrogen }= \\
& \frac{\mathrm{H}_{2} \mathrm{O} \text { Emission through Hydrogen Energy System }}{\text { Natural Water Vaporization }}
\end{aligned}
$$

The quantity of natural carbon cycle on the earth is $150 \mathrm{G}$ ton/year and the carbon emission by the fossil fuel is $5.5 \mathrm{G}$ ton/year as in Fig. 4. Then, the EIF for carbon on the earth in average can be calculated to be 0.036 . This is an important number. At this moment we are very much anxious about the global warming caused by the huge usage of fossil fuels and the EIF of carbon is 0.036. This means that the EIF of energy carriers should be less than 0.036 to obtain a sustainable growth of human beings.

If all the energy systems were used the hydrogen/water path, we could calculate the EIF of hydrogen on the earth in average. That is 0.0001 . This number is so small that we need not worry about the global warming when we use the hydrogen energy system with renewable energies as primary energy sources.

In the same way we can calculate local EIFs. Figure 6 and 7 show the local EIF of prefectures and big cities in Japan relating to the density of energy consumption. As the density of energy consumption increases both EIFs of carbon and hydrogen increase in the same trend. The EIF of carbon is always larger than that of hydrogen. The difference is roughly 2 orders of magnitude. Table 3

\begin{tabular}{|c|c|c|c|}
\hline & EIF of Carbon & $\Rightarrow$ & EIF of $\mathrm{H}_{2}$ \\
\hline Earth & 0.036 & $1 / 360$ & $\sim 0.0001$ \\
\hline Japan & 0.88 & $1 / 150$ & 0.006 \\
\hline Tokyo Metrop. & 35000 & $1 / 300000$ & 0.12 \\
\hline
\end{tabular}

Table 3 Comparison of environmental impact factor (EIF) of carbon and hydrogen.

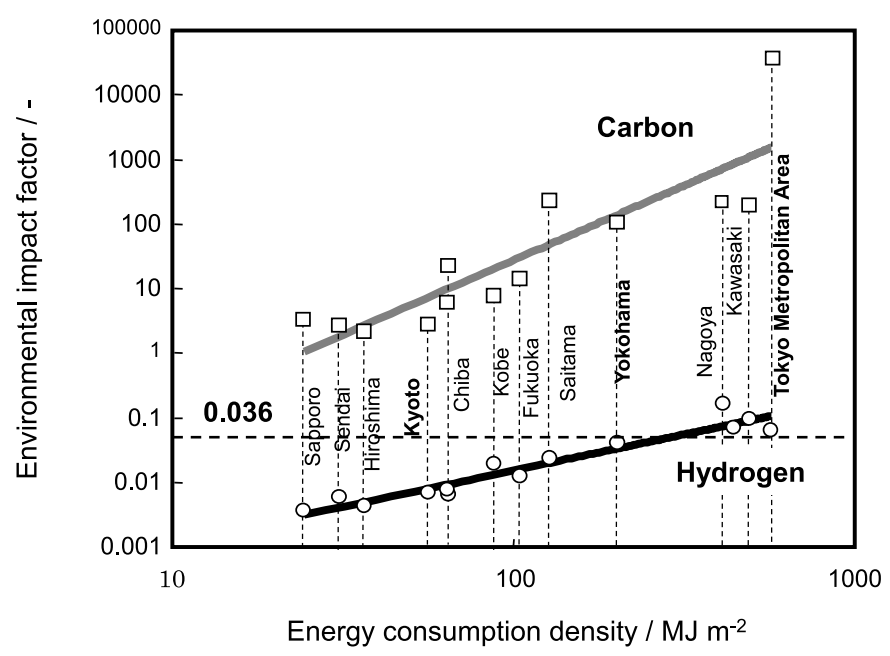

Fig. 7 Local environmental impact factor (EIF) of major cities in Japan. 


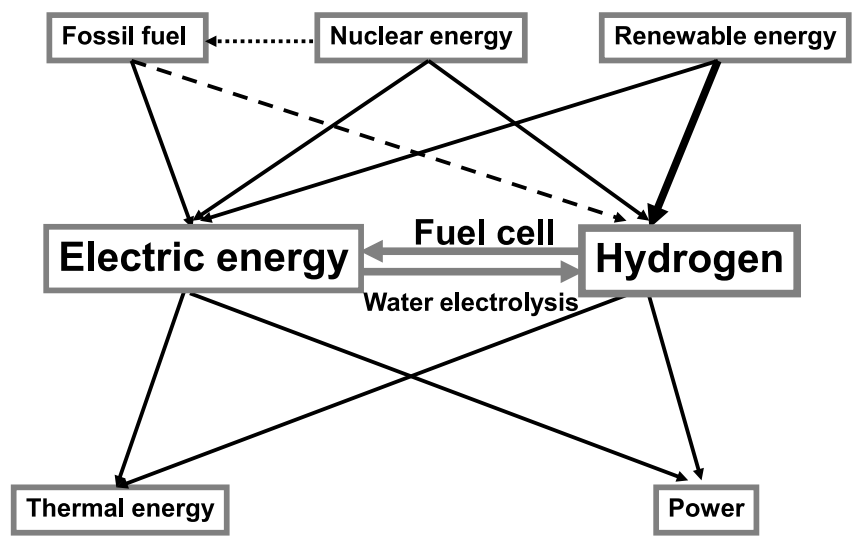

Fig. 8 Hydrogen energy system.

shows the comparison of EIF of carbon and hydrogen. The difference of EIF is very huge for Tokyo Metropolitan Area where the density of energy consumption is very large. This means the hydrogen energy system using renewable energies as primary energy is far environmentally friendly compared to the present fossil energy based system. Figure 8 shows the future hydrogen energy system. Hydrogen is a secondary energy and we have to use a primary energy to produce hydrogen. We can use any kind of primary energies to produce hydrogen. Hydrogen from natural gas is commercially produced in large scale. Hydrogen can be easily produced by the electric power from nuclear stations using water electrolysis.

However, we should not forget the final goal. Hydrogen should be produced using renewable energies. We would like to call hydrogen from renewable energies, "Green Hydrogen". We know renewable energies are so widely spread out and sometimes very local. It is not so easy for the usage of large consumption. But, we have technologies. Considering the sustainable growth of human beings in the future, the "Green Hydrogen" is only one solution

\section{Conclusions}

The global environment including the human society should stand on harmonizing with the Earth where the global cycles of materials are important. In this paper, it was clarified that the materials were circulated by the use of the low entropy of sunlight, and the low entropy was transferred to maintain the self-regulating activity by a chain of the materials circulation. This is an ideal state which the constancy and the stability of the Earth included the self-regulating systems could be guaranteed.

A water cycle is compared with a carbon cycle as a material circulation which mankind can utilize for the energy system. The annual movement from the atmosphere of water is 3160 times larger than that of carbon, so that a large difference occurs in the mean residence time in the atmosphere. In comparison with the carbon cycle, the water cycle is difficult to receive the effect of the mankind activity. The ratio of the energy consumption of mankind to the annual movement from atmosphere of water is more than two orders of magnitude less than that of carbon. The environmental impact factor (EIF) of hydrogen is far smaller than that of carbon. The water cycle is superior to the carbon cycle as material circulation for the energy system. "Green Hydrogen" (hydrogen from renewable energies) would be the final target for the sustainable growth of human beings.

\section{References}

1) M. A. Rosen and D. S. Scott, Int. J. Hydrogen Energy, 28, 1307 (2003).

2) M. A. Rosen and D. S. Scott, Int. J. Hydrogen Energy, 28, 1315 (2003).

3) M. A. Rosen and I. Dincer, Exergy Int. J., 1, 3 (2001).

4) E. Schrödinger, Cambridge, Cambridge University Press, p. 67 (1944) (Canto edition 1996).

5) I. Prigogine, W. H. Freeman and Company, SanFrancisco, CA, p. 5 (1980).

6) A. Tsuchida, Shigen Butsurigaku Nyumon (Introduction to Resources Physics), Nippon Housou Kyokai (1982) [in Japanese].

7) E. E. Conn and P. K. Stumpf, Outlines of biochemistry $4^{\text {th }}$, John Wiley \& Sons, NewYork, NY, p. 137 (1976).

8) A. L. Lehninger, Bioenergetics $2^{\text {nd }}$, W. A. Benjamin, Inc., p. 29 (1971).

9) J. P. Peixoto, A. H. Oort, M. D. Almeida, and A. Tome, J. Geophys. Res., 96, 10981 (1991).

10) I. Aoki, J. Phys. Soc. Jpn., 57, 3262 (1988).

11) A. Baumgartner and E. Reichel, The World Water Balance, Elsevier Scientific Pub. co. (1975).

12) E. K. Berner and R. A. Berner, Globlal water cycle, Geochemistry and Environment, Prentice-Hall, Inc., Englewood Cliffs, NJ (1987).

13) T. M. L. Wigley and D. S. Schimel, Ed., The carbon cycle., Cambridge University Press (2000). 